\title{
Um projeto de combate à sífilis nos sertões da Bahia
}

\author{
A fight project to syphilis in the Bahia backlands
}

\author{
Ricardo dos Santos Batista \\ Doutor em História \\ Professor Substituto da \\ Universidade do Estado da Bahia \\ rsbatista@uneb.br
}

Resumo: Esse texto tem como objetivo analisar como o projeto de combate à sífilis, proposto pelo sanitarista Eduardo Rabello e um grupo de pesquisadores do Instituto Oswaldo Cruz, foi desenvolvido nos sertões baianos a partir da criação do Departamento Nacional de Saúde Pública, em 1920. A política sanitária esteve em torno do debate sobre a prostituição, considerada principal veículo transmissor de doenças venéreas. Com a utilização de relatórios médicos do Serviço de Profilaxia Rural e a legislação Estadual e Nacional, busca-se discutir como diferentes cidades do interior baiano lidavam com a sífilis, e quais as principais dificuldades de implementação do projeto. Constatou-se a falta de enfermeiras visitadoras, que ocupavam papel central na proposta de profilaxia da sífilis, mas o que não impedia que o trabalho continuasse a ser desenvolvido.

Palavras-chave: Sanitarismo, sífilis, Bahia.

\begin{abstract}
This paper aims to analyse the project to fight against syphilis, proposed by the sanitarian Eduardo Rabello and a group of researchers from the Oswaldo Cruz Institute. Such a project was developed in the Bahia backlands since the creation of the National Department of Public Health in 1920. The health policy was around the debate on prostitution and considered it the main means of transmitting venereal diseases. With the use of medical reports Rural Prophylaxis Service and state and national legislation, this paper seeks to discuss how different cities of Bahia dealt with syphilis, and what are the main difficulties in implementing the project. It was found the lack of visiting nurses, who occupied central role in the proposed prophylaxis of syphilis, but that did not stop the work continues to be developed.
\end{abstract}

Keywords: Sanitarism, syphilis, Bahia. 


\section{A Reforma Sanitária e um projeto de saneamento dos Sertões}

Ao longo da segunda década do século XX, médicos sanitaristas participaram de viagens científicas aos sertões do território brasileiro. Organizadas pela União, tinham o objetivo de incorporar espaços distantes e desconhecidos pela maior parte das autoridades e da população dos grandes centros urbanos, e realizar um processo de integração nacional. Segundo Dominichi Sá (2009: 186), as origens desse projeto já podiam ser observadas no Império, mas, durante a República, iniciativas se intensificaram e ganharam nova expressão: 'incorporação' e 'conhecimento científico' faziam uma aliança que incluía levantamentos nosológicos e atividades de combate a doenças nos sítios a serem ocupados e povoados.

Estas viagens deram origem a importantes documentos, que auxiliaram a tornar visíveis as doenças que assolavam as camadas economicamente subalternas brasileiras residentes nos sertões. O relatório da expedição médico-científica do Instituto Oswaldo Cruz - IOC, chefiada pelos médicos Belisário Penna e Arthur Neiva, realizada ao Norte e Nordeste do país, no ano de 1912, por exemplo, teve grande repercussão entre as elites brasileiras. A ida ao sertão - com passagem pela Bahia, além do Piauí, Pernambuco e Goiás - foi uma solicitação da Inspetoria de Obras contra as Secas, órgão do Ministério dos Negócios da Indústria, Viação e Obras Públicas (SÁ, 2009: 184). O documento denunciava a situação de atraso do sertão, não por questões raciais, como se observou ao longo do século XIX, mas pelo abandono estatal e pelas inúmeras doenças que acometiam sua população. Percebeu-se que os sertanejos padeciam de moléstias diversas, como o impaludismo, principalmente após a vazante dos rios, a asma e inúmeras doenças dos olhos, tais como conjuntivite, blefarite e leucoma, com maior incidência a partir da cidade de Caracol, no Piauí. O diagnóstico da elevada disseminação da tuberculose e da sífilis no interior do Nordeste, acima até mesmo da leishmaniose, da bouba e da lepra, causou grande surpresa aos pesquisadores (THIELEN, 1992: 56).

Em análise sobre a redefinição dos sertões pelo grupo pró-saneamento rural, Gilberto Hochman (1998) identificou as linhas gerais que nortearam as ações do sanitarismo brasileiro. Os médicos entendiam que a doença caracterizava a sociedade, desafiava suas elites e as instituições políticas, e exigia um aumento da responsabilidade do poder público ao nível federal uma vez que a maioria dos estados não tinha condições técnicas e financeiras para implementar políticas de saúde. O movimento foi determinante 
para forjar uma consciência sanitária entre as elites brasileiras, o que possibilitou o surgimento das primeiras políticas de saúde e saneamento de âmbito nacional.

O Brasil passou a ser visto, ao mesmo tempo, como um grande hospital e um vasto sertão. Um marco que contribuiu para essa caracterização foi o pronunciamento realizado em 1916, pelo médico Miguel Pereira, em recepção a Aloysio Castro, diretor da Faculdade de Medicina do Rio de Janeiro - FMRJ. Sua fala tinha como objetivo responder aos pronunciamentos do deputado federal Carlos Peixoto, que teria demonstrado disposição, em função do conflito da Primeira Guerra Mundial, a ir aos sertões convocar os caboclos para o exército brasileiro, de modo a defender o país. A ideia de "grande hospital e vasto sertão" leva à reflexão sobre as fronteiras materiais entre os grandes centros e o que se considerava sertão: acreditava-se que os sertões começavam no final da avenida Rio Branco, boulevard de grande destaque no Rio de Janeiro (HOCHMAN, 1998). Isso evidencia a distância, também no plano simbólico, entre as cidades e o universo rural. "O hospital” significava, então, a presença de inúmeras endemias rurais em todo o território nacional e os sertões representavam o abandono da população pobre pelo poder público ou mesmo a sua completa ausência. Ao fazer uma analogia entre a proposição carioca e o contexto da Bahia na Primeira República, Christiane Souza (2013: 47) sugere que o "sertão" começava "para os lados" da avenida Sete de Setembro, tomada como ícone de progresso e modernidade pelo governador J.J. Seabra e cujo modelo era a capital da República. Mas, apesar da salubridade e ordenação do espaço urbano pretendidas pelo líder político e seus correligionários, a vida das camadas mais pobres de Salvador pouco diferia da do povo pobre do interior do estado.

Na segunda década do século XX, a proposta de centralizar os serviços sanitários era um desfio à política vigente, devido à instituição do regime federalista, implantado com o advento da República, e que teve Belisário Penna como um dos seus principais críticos (cf. SANGLARD, 2008: 126-127). Para os sanitaristas, no entanto, o instrumento legal que tornaria viável essa ação seria um código sanitário válido em todo o país e executado pela autoridade sanitária federal, o que não eliminaria a necessidade de os estados e municípios criarem seus próprios serviços sanitários: “[...] a autonomia dos serviços federais, que deveriam ser exclusivamente técnicos, seria a prevalência da ciência contra os interesses políticos, alvo das críticas do movimento" (HOCHMAN, 1998: 224- 225).

Como resultado dos esforços realizados pelos sanitaristas brasileiros, o Presidente da República, Epitácio Pessoa, promulgou o decreto n. 3.987, em 2 de janeiro de 1920, 
com o intuito de reorganizar os serviços da saúde e criar o Departamento Nacional de Saúde Pública - DNSP que, entre muitas atribuições, tornava-se responsável pela execução dos serviços de higiene e saúde pública no Brasil e ampliava o papel do Estado nos processos sanitários (BRASIL, 1920). No ano de 1922, 16 dos 21 estados da federação, mais o Distrito Federal, já haviam firmado acordo com a União para serviços de profilaxia e combate às endemias rurais (HOCHMAN, 1993: 51), o que possibilitou a constituição de novas estruturas administrativas para o tratamento de inúmeras doenças. Com esses acordos, profissionais da saúde passaram a se deslocar pelo vasto e desconhecido território brasileiro, no trabalho de organização sanitária e combate às endemias, e utilizavam como instrumento principal a educação sanitária, norteadora da proposta nacional. A Bahia foi um dos estados nos quais o projeto sanitarista foi desenvolvido, a partir de um acordo com o Governo Federal, realizado no dia 15 de abril de 1921, para um período de três anos e, em 29 de fevereiro de 1924, renovado por mais cinco anos (BARRETO, 1927: 175). Entre os serviços a serem desenvolvidos estavam a Profilaxia Rural para o combate à lepra, sífilis e às doenças venéreas, de luta antituberculose e de higiene infantil.

A renovação do acordo sanitário contou com a supervisão do médico Antônio Luis Cavalcante Albuquerque de Barros Barreto. Ele fez parte de um grupo de sanitaristas que se aperfeiçoaram profissionalmente no exterior e, depois, assumiram cargos importantes no campo da saúde em diversos estados do Brasil. Barros Barreto frequentou o IOC, onde matriculou-se no Curso de Microbiologia e Zoologia Médica, concluído em 1914. Foi convidado, por Oswaldo Cruz, a continuar pesquisando na sessão de Zoologia e elaborou a tese de doutoramento intitulada Revisão da família Subulinae. Trabalhou no IOC como assistente efetivo entre 1919 e 1921, até ser transferido para o lugar de Inspetor Sanitário do Departamento Nacional de Saúde - DNS. Ingressou, em 1915, como interno na Clínica Sifilográfica e Dermatológica da FMRJ, onde Eduardo Rabello foi catedrático e, possivelmente, lhe colocou em contato com ideias que gerariam a política sanitária de combate à sífilis. Em 1922, viajou para a América do Norte, cursou a Johns Hopkins University e diplomou-se doutor em Saúde Pública. Especializou-se, em Paris, no Hospital Saint Louis, recebendo o diploma de "Dermologia e Venereologia" pela Faculdade de Medicina da Universidade de Paris. O médico possuía o perfil esperado para a manutenção dos serviços de saúde na Bahia, com uma sólida formação relativa às doenças venéreas. Mudou-se em 1934 para Salvador e contraiu matrimônio com a filha do governador Francisco Marques de Góes Calmon (JACOBINA, 2013: 37-44). 
Além de Barros Barreto, que comandou o desenvolvimento da política de combate à sífilis, outros profissionais da saúde também realizaram aprimoramento profissional, em diálogo com o IOC ou centros de referência em saúde no exterior. No curto espaço de tempo de um ano e meio, foram enviados oito médicos ao sul do país, para visitar as organizações sanitárias de São Paulo, Distrito Federal e Minas Gerais, frequentar o Instituto Manguinhos e realizar os cursos de Malariologia e de Saúde Pública. No ano de 1927, viajaram dezoito médicos e duas enfermeiras para o Rio de Janeiro e exterior, como o doutor Álvaro Garcia Rosa, Guilherme Ramos e Álvaro Garcia Rosa para formação na Capital Federal (BARRETO, 1928: 26).

Ao se perceber a necessidade de adequação da legislação do estado ao código sanitário de 1920, foi criada a Subsecretaria de Saúde e Assistência Pública e, em meados de 1925, promulgado o Código Sanitário da Bahia. O novo órgão, diretamente subordinado a Góes Calmon, passou a gerir os serviços de higiene e saúde pública executados no estado, a partir de então. Cabia à Subsecretaria o estudo de todas as questões que interessassem à saúde coletiva; a adoção de todas as medidas técnicas que viessem evitar, diminuir e suprimir as causas de doença e de morte; e o melhoramento das condições de saúde e bem-estar da população (BAHIA, 1925: 5-6).

Uma grande novidade na criação do novo órgão da estrutura sanitária baiana foi a regulamentação do tratamento das doenças venéreas, o que denota a importância que esse campo da saúde ganhava desde fins do século XIX. O Serviço de Profilaxia da Lepra e Doenças Venéreas tornava-se responsável pelo tratamento dos doentes de sífilis e enfermidades venéreas transmissíveis, atendendo principalmente aos portadores de lesões contagiosas e "[...] ministrando-lhes os conselhos necessários para uma cura definitiva" (BAHIA, 1925: 22). Esse serviço mantinha uma estreita relação com a proposta nacional e, mesmo com as especificidades presentes na implantação de uma proposta sanitária em diferentes localidades do extenso território brasileiro, foi realizado nas cidades do interior baiano.

\section{Uma proposta nacional de combate à sífilis}

A Inspetoria de Profilaxia da Lepra e Doenças Venéreas - IPLDV, encarregada, também, da profilaxia do câncer, e criada com a Reforma Sanitária de 1920, tinha como 
um grande objetivo o combate à sífilis. Conforme identificado nas viagens científicas do IOC, a doença assolava os sertões e impedia os baianos de gozar de bem-estar. No $1^{\circ}$ Congresso Sul-Americano de Dermatologia e Sifilografia, ocorrido no Rio de Janeiro em 1918, os sifilógrafos Eduardo Rabello e Oscar Clark enfatizavam a presença constante da sífilis nos sertões. Para o primeiro, o Brasil diferia da maioria dos países civilizados, onde a enfermidade preferia ser antes "cidadã" que "camponesa":

\begin{abstract}
Em nosso país, sem que nos balancemos a dizer que a fórmula se inverteu, estamos todavia autorizados a dizer que mesmo nos campos a proporção dos casos é notável. Assim, depõem com clamorosa unanimidade todos os médicos que, como Carlos Chagas, Arthur Neiva e outros, cruzaram viagens científicas no nosso interior (RABELO, 1921 apud CARRARA, 1996: 119).
\end{abstract}

Coube a Eduardo Rabello a direção da IPLDV. Ele atuou como auxiliar técnico do Laboratório de Bacteriologia da FMRJ, desde 1906. Tornou-se professor substituto da instituição, em 1915. Além disso, ocupou o cargo de secretário da Sociedade de Dermatologia e Sifilografia, em 1912, e foi enviado à Europa pelo Diretor Nacional de Saúde Pública, Carlos Seidl, em 1914, para estudar as medidas antivenéreas que lá eram adotadas no combate à sífilis (CARRARA, 1996: 91). Apesar de vinculado à FMRJ, Eduardo Rabello desenvolveu com Oscar da Silva Araújo, seu parceiro e substituto na direção da IPLDV a partir de 1927, um plano de combate à sífilis, com forte vinculação ao IOC, onde escreveu a tese de doutoramento intitulada Hematologia na ancilostomose.

A proposta de Eduardo Rabello, explicitada no regulamento do DNSP, surgiu em meio ao debate sobre regulamentação e abolição da prostituição, que provocou calorosas discussões, atravessando o século XIX. O meretrício era considerado pelos médicos o principal veículo de transmissão da doença e, portanto, deveria sofrer interferência de sua parte. O regulamentarismo via a prostituição como um mal necessário e acreditava que, se fixadas nos bordeis, as meretrizes poderiam ser submetidas a uma vigilância constante, da qual fazia parte o controle médico obrigatório e regular, para serem internadas em hospital especial no caso de estarem doentes. Em sua primeira versão, essa perspectiva tinha como objetivo combater a libertinagem, proteger a moral familiar, disciplinar o espaço público e a mulher pública para que os homens não ferissem a moral das mulheres "honestas". Por outro lado, o abolicionismo se propunha a um combate simultâneo à prostituição e às doenças venéreas, considerando a contenção sexual masculina e a 
emancipação política da mulher como meios mais eficientes para acabar com a prostituição e com as doenças que ela transmitia. Educação e propaganda seriam os instrumentos privilegiados para alcançar tais objetivos (CARRARA, 1996: 167,171).

A partir de críticas abolicionistas relacionadas à "eficácia da regulamentação", já que muitas mulheres poderiam fugir à inscrição e aumentar o número de clandestinas; ao “critério jurídico-político", pois o regulamento colocava as prostitutas fora do direito comum e sob o arbítrio direto da polícia; e à "moralidade", visto que se reconhecia a prostituição como profissão, originou-se o neorregulamentarismo, que teve como principal formulador o sifilógrafo francês Alfred Fournier, defensor da regulamentação não mais em nome apenas da preservação moral e dos bons costumes, ou do saneamento moral dos espaços públicos, mas por razões de ordem sanitária. Secundário no início, o combate às doenças venéreas transformou-se em justificativa essencial do neorregulamentarismo de finais do século XIX (CARRARA, 1996:172). Esse grupo também incorporou várias das propostas abolicionistas, principalmente a defesa de uma ampla campanha de educação antivenérea para alertar a população sobre os perigos das doenças sexuais.

Os conflitos entre regulamentaristas e abolicionistas tinham como fundo a oposição entre lei e educação. Também chamados de modelo "jurídico-punitivo" e “pedagógico-disciplinar", em linhas gerais divergiam fundamentalmente sobre o modo como a sexualidade humana deveria ser compreendida. Para os primeiros, a questão principal não era mudar o comportamento sexual masculino, nem recuperar as prostitutas, mas submetê-las a exames periódicos, não propondo mudanças profundas nos comportamentos individuais, pois acreditavam que a prostituição era uma instituição sem chances de ser excluída do meio social (CARRARA, 1996: 204). Por outro lado, os abolicionistas tendiam a discordar dos regulamentaristas quanto à natureza dos desejos sexuais. Para eles homens e mulheres poderiam e deveriam ser castos, podendo ser erradicado o meretrício e educada a população. Segundo Carrara, a esse respeito havia divergências cruciais quando se discutia o tipo de informação médica a ser divulgada. A partir dessas disparidades, originaram-se, em linhas gerais, um abolicionismo "moral" e um abolicionismo "científico". Enquanto que, para os moralistas, o tratamento para doenças sexuais era visto com desconfiança, porque a enfermidade deveria continuar a significar uma vida de desregramento sexual, os adeptos do "abolicionismo científico" acreditavam ser necessário o combate à doença a partir de todos os meios possíveis. Nesse caso, divulgava-se a necessidade de restrição sexual masculina ao casamento, mas não se 
privava de oferecer informações sobre como evitar doenças venéreas por meios técnicos, como o uso de pomadas desinfetantes, lavagens, preservativos, entre outros.

Depois de muitas discussões a respeito das vantagens e desvantagens desses modelos, inclusive após a Proclamação da República, quando o debate sobre as medidas de profilaxia sanitária voltou à tona, a proposta regulamentarista foi derrotada pelo abolicionismo. Apesar disso, a liberdade proporcionada pelo regime federalista permitiu a implantação de medidas diversas no país, como as essencialmente jurídico-punitivas levadas a cabo pelo sanitarista de Manguinhos, Heráclides Cesar de Souza Araújo, nos estados do Paraná e Pará. Mesmo se posicionando contra o modelo adotado por Souza Araújo e defendendo o abolicionismo, é possível afirmar que Eduardo Rabello se aproximou muito mais de alguns regulamentaristas do que dos abolicionistas morais e conseguiu articular um grupo com ideias semelhantes para o combate à sífilis no Brasil, na segunda década do século XX, a partir de um modelo baseado na concepção de higiene:

[...] as experiências regulamentaristas de Souza Araújo logo se chocariam com as novas diretrizes nacionais da luta antivenérea no Brasil, através da constituição de um extenso sistema de profilaxia articulado pelo governo central. Aparentemente, as intermináveis querelas entre abolicionistas e regulamentaristas começavam a ser superadas. Assumindo [...] posições estratégicas em instituições cientificas e acadêmicas, um grupo bastante coeso de sifilógrafos, organizado desde 1912 em torno da Sociedade Brasileira de Dermatologia e Sifilografia, conseguia formular uma "solução" a um só tempo pragmática e conciliadora para o problema venéreo brasileiro (CARRARA, 1996: 218. Grifos do original).

A nova legislação estava a meio caminho entre abolicionismo e regulamentarismo: defendia a restrição sexual masculina apenas para que a proposta tivesse aceitação na sociedade e não por moralidade. Por outro lado, através da educação sanitária, conseguiria disseminar uma série de medidas de profilaxia, como os conhecimentos de técnicas de prevenção, pomadas e soluções desinfetantes depois das relações sexuais. A base da profilaxia proposta estava sobre dois pilares principais: a campanha de propaganda e educação higiênica e o tratamento profilático. Buscava-se impedir o contágio pelo diagnóstico precoce e tratamento eficaz dos doentes, assim como proteger os indivíduos sãos, esclarecendo-os quanto aos perigos que corriam e a que 
expunham seus descendentes (CARRARA, 1996: 220-221). Para tanto, determinava-se que a cura deveria ser realizada, de preferência, nos dispensários e, em certos casos, em hospital especial ou em enfermarias anexas aos hospitais gerais (BRASIL, 1920a, art. 505); os dispensários deveriam ser instalados em locais acessíveis, mas discretos; o atendimento deveria ser realizado segundo o sexo e condição social dos pacientes; era necessário um pequeno laboratório para exames microscópicos das doenças venéreas e/ou sorológicas, sendo que os exames poderiam ser facultados aos doentes de poucos recursos que estivessem se tratando fora dos dispensários, quando fosse preciso esclarecer o diagnóstico do caso contagiante (BRASIL, 1920a, art. 510); entre outras orientações.

O Regulamento Sanitário de 1920 determinava, por exemplo, que as pessoas de ambos os sexos, pelos seus hábitos, ocupação, meio de vida ou por outra qualquer causa evidente, se tornassem suspeitas de estar infectadas ou de veicular os germens daquelas doenças; e as que fossem aptas a transmiti-las mais facilmente, mereceriam cuidados especiais da autoridade sanitária. Isso pode ser interpretado como uma alusão ao cuidado especial a ser dispensado às meretrizes (CARRARA, 1996: 222). A adoção de um "serviço social" com enfermeiras visitadoras, como foi proposto pelo DNSP (BRASIL, 1920a, art. 498), era central em um modelo regulamentarista, visto que elas se encarregariam de encontrar as prostitutas e convencê-las a se matricularem em um dispensário, a serem examinadas e tratadas.

Um empreendimento que contribuiu significativamente para o combate à sífilis, no Rio de Janeiro, pode ser observado na obra Entre os salões e o laboratório. Nela, Gisele Sanglard reconstruiu aspectos relativos à articulação entre bacteriologia e filantropia e analisou como o benemérito Guilherme Guinle desenvolveu uma íntima relação com o projeto de saúde pública representado pela IPLDV. Para a autora, com a impossibilidade do estado assumir o combate em defesa da saúde em todas as frentes propostas, expressas na reforma da Saúde Pública e no Regulamento Sanitário, Carlos Chagas, diretor do DNSP, apostou no consórcio com a iniciativa privada. Com isso, o projeto do médico pôde ser colocado em prática, num contexto em que um grupo de intelectuais e médicos pensava os destinos da nação por meio da salvação do homem brasileiro e colocava a ciência a serviço da construção nacional (SANGLARD, 2008: 261-262).

Como resultado dessa relação, criou-se um complexo hospitalar sob a fiscalização de Eduardo Rabello e Gilberto Moura Costa, não apenas para o tratamento da sífilis, mas para o desenvolvimento de pesquisa. Tinha-se o intuito de realizar um melhor diagnóstico 
e encontrar terapias para a doença, dando projeção às atividades da Fundação Gaffré e Guinle. As ações da Fundação iniciaram-se com os primeiros ambulatórios, estruturados para dar suporte ao funcionamento do hospital. A localização dos mesmos evidenciava o cuidado em controlar boa parte da cidade, acompanhando a expansão natural que o Rio de Janeiro vivia em direção aos subúrbios (SANGLARD, 2008: 176-178; 171). Quando criado, o hospital desempenhava, com ênfase, uma função socioeducativa.

Foi a partir desse modelo educativo-higiênico que a IPLDV orientou o combate à sífilis no Brasil, a partir de 1920. Como poderá ser observado, os médicos baianos encontraram algumas dificuldades no processo de implantação das diretrizes nacionais, mas isso não os impediu de promoverem ações e, diante das condições materiais existentes, colocarem em prática o projeto.

\section{0 combate à sífilis nos sertões baianos}

A sífilis era uma doença que grassava no interior da Bahia, matando inúmeros sertanejos e debilitando tantos outros. Dois estudos históricos baianos analisam a sua existência em cidades específicas, Feira de Santana e Jacobina, em períodos distintos; ademais, articulam o baixo índice de sifilíticos nos atestados de óbitos a questões morais que existiam em torno da doença.

Os oito livros de óbito pertencentes aos registros eclesiásticos de morte da cidade de Feira de Santana, fonte de investigação de Aldo Silva, apontam para a existência de apenas 10 sifilíticos ao longo do intervalo 1828-1894, período que engloba praticamente todo o século XIX (SILVA, 1999: 106). Para o autor, o prestígio pessoal e político e fortes tradições familiares impediram que homens brancos, livres e casados fossem registrados como portadores da doença. Em consonância com essa interpretação, o estudo sobre Jacobina também esteve pautado nos detalhes dos atestados post-mortem e no questionamento sobre a inexistência de ourives, advogados e médicos registrados como sifilíticos, em contraposição a padeiros, carpinteiros e pessoas que ocupavam posições de baixo poder aquisitivo (BATISTA, 2014: 61-68; BATISTA, 2013). Além disso, nos mesmos estudos foram exploradas as condições sanitárias daquela cidade no auge da exploração do ouro, assim como a recorrência a outras práticas de cura, diferentes das práticas institucionais, e a ações de curandeiros que produziam "garrafadas" como forma de tentar aliviar o mal que a sífilis trazia. Aqui, não se buscará interpretar significados da 
ausência ou presença da doença em óbitos, mas se procurará perceber como ocorria o tratamento da sífilis em algumas cidades baianas, observando aspectos relativos às especificidades locais, no cumprimento das orientações federais para o combate à doença.

Em relação ao atendimento à sífilis, no ano de 1926 duplicaram-se os oito Postos de Saneamento Rural que existiam em 1924. Essas instituições tinham o objetivo de combater as grandes endemias dos campos, como helmintoses e impaludismo, mas também de se ocupar da higiene das habitações, da profilaxia da sífilis e doenças venéreas, do cadastro e recenseamento populacional, além da luta contra as doenças infecciosas (BARRETO, 1927: 9). Os médicos desenvolviam ações nessas instituições, e promoviam a educação sanitária, para o desenvolvimento da proposta de saneamento dos sertões, o que incluía, também, outras doenças que não a sífilis:

Os médicos do interior investiam na profilaxia de doenças mediante a educação sanitária. Em Ilhéus, São Félix, Cruz das Almas e Santo Amaro, por exemplo, eram distribuídos impressos educativos [...], ensinando os meios de evitar a febre tífica. Além disso, solicitava-se que todos os clínicos locais notificassem qualquer caso suspeito vindo da zona rural da cidade, para que se ministrasse o procedimento necessário o mais breve possível (BATISTA, 2015: 194-195).

A educação sanitária se dava através da circulação de cartazes, realização de palestras e atividades em escolas situadas na sede das cidades contempladas com os Postos de Saneamento Rural. Nesse sentido, a Subsecretaria de Saúde e Assistência Pública enviava ao interior cartazes que faziam alusão à importância de se frequentar os dispensários de doenças venéreas para o devido tratamento. No exemplo a seguir, é possível observar pessoas aglomeradas na porta do posto profilático, para serem atendidas pelo médico. Nota-se que a imagem é composta apenas por homens, já que havia questões morais que impediam as mulheres de serem representadas. Estabelecia-se uma ligação entre sífilis e moralidade que relacionava as mulheres portadoras de sífilis à prostituição, conforme demonstrou Batista (2014).

\section{Imagem 1}

Propaganda da Secretaria de Saúde e Assistência Pública da Bahia. 


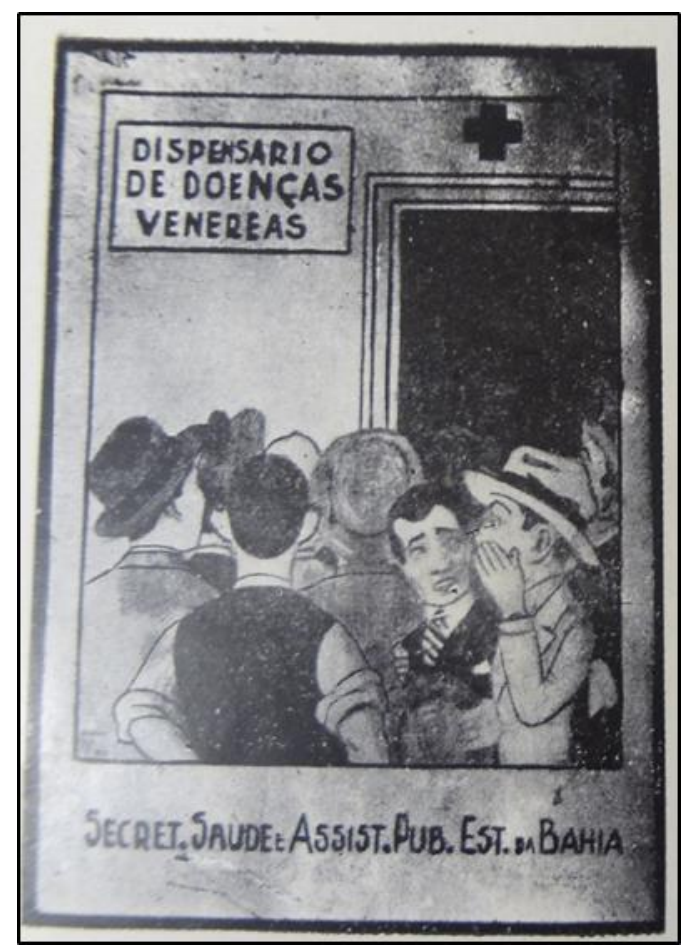

Fonte: BARRETO, 1928.

O serviço de profilaxia da sífilis teve, talvez, em Santo Amaro, cidade situada no Recôncavo baiano, o melhor desempenho da década de 1920. Os resultados eram tão positivos que, em 1926, o médico Taciano de Britto recebeu a visita dos colegas Guilherme Silveira, chefe do posto da cidade de Alagoinhas, e Durval Pires, do posto de saneamento de Jequié, no intuito de observar como se desenvolviam as ações naquela instituição. Segundo o doutor Britto, seus colegas de profissão se esforçaram para conhecer as atividades desenvolvidas no ambiente e acompanharam-no em todos os trabalhos cotidianos e seus detalhes (BRITTO, 1926). Esse é um exemplo de como, no projeto que se propôs ser desenvolvido, os profissionais que atuaram nos sertões baianos estavam articulados, compartilhavam informações e experiências relacionadas à prevenção e combate às enfermidades.

O tratamento das doenças venéreas de Santo Amaro ocorria em uma sala específica, na qual funcionava o dispensário de sífilis, tendo atingido, naquele ano, 745 indivíduos de ambos os sexos. Os curativos e injeções eram realizados todos os dias úteis, no turno da tarde, em dias alternados para homens e mulheres, visando a uma melhor disposição do serviço, conforme determinava o regulamento de 1920. Os curativos das mulheres eram feitos pela enfermeira Adalgiza Bastos, a quem também cabia a tarefa de visitar o meretrício, nas várias ruas da cidade (BRITO, 1926). De fato, o plano nacional 
de combate à sífilis não regulamentou a prostituição, mas elegeu as enfermeiras visitadoras como meio de atingir as meretrizes. Nas visitas realizadas, a enfermeira santoamarense buscava convencer as mulheres da rua a utilizarem os serviços do posto como medida de saúde individual e de higiene.

Nos anos seguintes, o posto de profilaxia rural daquela cidade aumentava o número de atendidos, notadamente de pessoas que haviam contraído a sífilis (BRITTO,1928; BRITO,1929). O doutor Britto ressaltava a existência do material necessário para o cuidado com a saúde da população sifilítica, ao mesmo tempo em que contrapunha o tratamento oferecido pelo Posto àquele oferecido pelo Hospital da Santa Casa de Misericórdia de Santo Amaro:

[...] com o suprimento de ampolas mercuriais e com modesto material cirúrgico de que dispõe o Posto, se vai atendendo aos clientes de ambos os sexos, que já hoje bendizem a criação deste Dispensário, recurso que faltava a uma cidade de que só dispõe de um hospital onde a medicina oficial não existia (BRITTO, 1926).

Ticiano de Britto demonstrava-se satisfeito com o tratamento realizado no dispensário, mas não se satisfazia com o local onde o posto funcionava. Três anos depois aguardava, com ansiedade, que o prefeito cedesse um espaço no térreo do prédio da prefeitura, para onde almejava transferir o posto de profilaxia rural. Para ele, os trabalhos poderiam ser realizados com um serviço "mais complexo", em um espaço mais adequado (BRITTO, 1929). Em relação aos medicamentos utilizados no tratamento da sífilis, eram ministradas substâncias recorrentes na capital e outros municípios brasileiros, como o mercúrio, o bismuto e o Neosalvarsan (BRITO, 1929; BRITTO, 1928).

No que diz respeito à disponibilidade de materiais clínicos, uma realidade diferente de Santo Amaro existia na cidade de Itabuna, no sul do estado. Apesar do serviço de profilaxia da sífilis ser o mais concorrido pelos pacientes que visitavam o posto, o chefe sanitário queixava-se da impossibilidade de realizar a reação de Wasserman, principal exame clínico utilizado para identificar a sífilis no período, ou outra análise esclarecedora sobre ela, devido ao microscópio ultrapassado (MIRAVEL, 1925). Por outro lado, o serviço de combate às doenças venéreas contemplava a disponibilização de duas horas diárias para consultas, conforme determinava o regulamento sanitário (MIRAVEL, 1925). Aberto das 8 às 10h, com essa finalidade, enquanto um funcionário 
aplicava injeções intramusculares, outro fazia os curativos, um terceiro cuidava das matrículas, o médico examinava os novos doentes, fazia aplicação de injeções endovenosas e fiscalizava o serviço. Nessas condições, o diagnóstico da sífilis requeria uma ampla experiência do médico que, sem a possibilidade de realizar exames sorológicos, conseguia identificar melhor as infecções quando os pacientes apresentavam manifestações cutâneas.

Para o chefe dos serviços de profilaxia da sífilis e doenças venéreas de Itabuna, os benefícios trazidos aos pobres daquela cidade foram incalculáveis. Como grande parte dos doentes podia adquirir os medicamentos, ele médico receitava para que comprassem em farmácias, guardando os medicamentos do posto para aqueles que fossem reconhecidamente indigentes. O serviço atendeu a um número considerável de meretrizes no ano de 1925, às quais se prestava todos os cuidados, esclarecendo-lhes quanto à profilaxia das moléstias venéreas e aconselhando-as sobre a adoção de medidas fáceis e úteis. Naquele posto, as pessoas se tratavam e recebiam instruções preventivas contra infecções venéreas, o serviço de Educação e Propaganda era eficaz e, sempre que possível, era distribuído grande número de folhetos e boletins de propaganda sanitária por todo o interior do município.

Bem próximo de Itabuna, a cidade de Ilhéus também acumulava problemas relativos aos equipamentos para os postos sanitários. O dispensário tinha movimento regular, mas o diagnóstico da sífilis também era realizado apenas reunindo os sinais clínicos do doente. Como a maior parte dos dispensários do interior da Bahia, a cidade contava com um microscópio ultrapassado, que servia apenas para a realização de exames simples, como fezes e urina. Nesse caso, além do microscópio, o material para a realização de Wassermann compunha os itens de solicitação ao Subsecretário de Saúde e Assistência Pública, numa visível percepção, do doutor Guimarães, sobre a importância do diagnóstico precoce da sífilis:

Ora, sabe-se quanto é isso falível. Urge que a Diretoria do Saneamento envie para o Dispensário não somente um microscópio bom, com dispositivo de ultramicroscopia, como também o material indispensável para a reação de Wassermann. Isto não acarretará grande despesa, pois o Posto poderá cobrar os exames que fossem pedidos para doentes estranho pelos clínicos locais (GUIMARÃES, 1926). 
Diferente dos dispensários de Itabuna e Santo Amaro, em Ilhéus o número de mulheres que se tratava no posto profilático era pequeno: nos oito meses de funcionamento do posto, 18 haviam comparecido para o tratamento da gonorreia e 4 para o tratamento da sífilis. O motivo da baixa frequência feminina era a falta de uma enfermeira que pudesse fazer o atendimento das mulheres. Segundo o chefe sanitário, os curativos venéreos, mesmo em mulheres, eram realizados por enfermeiros (homens):

É pois de grande utilidade uma enfermeira no Posto, que se dedique a tais curativos, que vá em domicílios, aconselhando o tratamento às rebeldes, chamando ao Dispensário outras que dele fogem, ofuscadas por uma cura aparente, explicando-lhes os meios de evitar a moléstia e o caminho a seguir quando doentes (GUIMARÃES, 1926).

O médico Gil Guimarães reiterava o pedido de nomeação de uma enfermeira, que pudesse fazer com mais desembaraço o tratamento de doentes femininas e, assim, evitar o desrespeito ao "pudor das pobres pacientes" que, em geral e principalmente para certas moléstias, recusavam-se terminantemente aos curativos praticados por enfermeiros (GUIMARÃES, 1926).

O mesmo ocorria na cidade de São Felix, em 1925. A matrícula de mulheres contaminadas com doenças venéreas tendia a se extinguir pela falta de uma enfermeira. Segundo o chefe sanitário, algumas ainda eram tratadas pela ex-enfermeira do posto, que prestava serviços eventualmente. Para ele, a cidade e, principalmente, o município de Cachoeira, eram localidades com grande número de prostitutas e muitas delas frequentavam o posto "a miúdo". O médico destaca que, para algumas, ele conseguia receitar e oferecer instruções precisas para o tratamento, mas, para outras, não. No ano seguinte, o médico se queixava de não conseguir informar o número de doentes curados de sífilis, pelo grande número de matriculados naquele posto. Logo que os doentes se sentiam melhor das afecções que os incomodavam, abandonavam o tratamento e retornavam, muitas vezes, mais doentes do que quando o haviam iniciado. Segundo o médico, havia um número que poderia estar curado se frequentasse assiduamente o dispensário.

Por fim, destaca-se que a falta de verbas municipais também funcionava como um empecilho para o combate à doença, em muitos municípios do interior da Bahia. Nesses locais, os efeitos do federalismo se manifestavam, entre outros aspectos, na recusa de 
muitos intendentes municipais a contribuir com as despesas necessárias para manter os postos em funcionamento.

\section{Considerações finais}

O projeto médico de combate à sífilis nos sertões da Bahia foi realizado a partir do acordo entre o estado e a União. É certo que havia diretrizes federais a serem seguidas, mas não se pode desconsiderar que as especificidades referentes aos diferentes contextos nos quais o plano foi desenvolvido interferiam na operacionalização das ações.

Muitas determinações como a disponibilização de hora específica para o tratamento de sifilíticos e o desenvolvimento de propaganda educativa puderam ser alcançadas na maior parte dos municípios. Contudo, a principal queixa que se observa nos relatórios analisados é a ausência de enfermeiras, que pudessem atender às mulheres portadoras de sífilis. Não se pode negar que a figura das enfermeiras - que fizesse curativos, mas que também realizasse visitas para convencer pessoas consideradas "suspeitas" a se tratar - era uma peça central na política nacional. Contudo, isso não quer dizer que a sua falta, em algumas localidades, inviabilizou o projeto.

Com avanços e dificuldades cotidianas, um plano de saneamento rural e de profilaxia da sífilis se tornava realidade também nos sertões. Se nos postos sanitários da capital havia problemas a serem enfrentados, conforme demonstraram Batista e Souza (2015), nos centros sanitários do interior havia muitos outros. As distâncias eram grandes, as redes de transporte escassas e os conflitos com os intendentes dos municípios contribuíam, às vezes, para que o trabalho não fosse desenvolvido com a regularidade esperada. Mas, mesmo assim, o trabalho continuava e, cada vez mais, os doentes de sífilis aderiam ao tratamento ministrado nos postos, em uma estrutura que se expandiu no Estado Novo.

\section{Fontes}

BARRETO, Antônio Luis C. A. de Barros (1927). Relatório da Secretaria de Saúde e Assistência Pública: anno de 1926. Salvador: Imprensa Oficial do Estado da Bahia. BARRETO, Antônio Luis C. A. de Barros (1928) Relatório da Secretaria de Saúde e Assistência Pública: anno de 1927. Salvador: Imprensa Oficial do Estado da Bahia. BAHIA (1925). Lei 1.811, de 19 de julho de 1925. Cria a Subsecretaria de Saúde e Assistência Pública. Salvador. (Arquivo Público do Estado da Bahia). 
BRASIL (1920a). Decreto n. 14.354, de 15 de setembro de 1920. Approva o regulamento para o Departamento Nacional de Saúde Pública, em substituição do que acompanhou o decreto n. 14.189, de 26 de maio de 1920. Diário Oficial dos Estados Unidos do Brasil, Rio de Janeiro, 16 set. Disponível em: $<$ http://legis.senado.gov.br/legislacao/ListaPubli cacoes.action?id=53975\&tipoDocumento=DEC\&tipoTexto=PUB $>$. Acesso em: 24 mar. 2016.

BRASIL (1920b). Decreto n. 3.987, de 2 de janeiro de 1920. Reorganiza os serviços da Saúde Pública. Diário Oficial dos Estados Unidos do Brasil, Rio de Janeiro, 2 jan.. Disponível em: <http://www6.senado.gov.br/legislacao/ListaPublicaco es.action?id=48173>. Acesso em: 1 jul. 2013.

BRITTO, Ticiano de (1926). Relatório dos trabalhos effectuados no Posto de Saneamento Rural de Santo Amaro. Caixa 4082, maço 114. (Arquivo Público do Estado da Bahia) (1928). Relatório dos trabalhos effectuados no Posto de Saneamento Rural de Santo Amaro. Caixa 4082, maço 114. (Arquivo Público do Estado da Bahia) (1929). Relatório dos trabalhos effectuados no Posto de Saneamento Rural de Santo Amaro. Caixa 4082, maço 114. (Arquivo Público do Estado da Bahia)

GUIMARÃES, Luiz Gil de Souza (1926). Relatório dos serviços prestados pelo Posto de Saneamento Rural de Ilhéos, 1926. Caixa 4082, maço 113. (Arquivo Público do Estado da Bahia)

(1928) Relatório apresentado ao Dr. Diretor do Saneamento Rural pelo Chefe do posto Rural de Ilhéos em Janeiro de 1928. Caixa 4082, maço 113. (Arquivo Público do Estado da Bahia)

MIRAVEL, A. Cordeiro de (1925). Relatório dos serviços realizados no Pôsto de Saneamento Rural de Itabuna. Caixa 4082, maço 113. (Arquivo Público do Estado da Bahia)

\section{Referências Bibliográficas}

BATISTA, Ricardo dos Santos (2015). Como se saneia a Bahia. A sífilis e um projeto político-sanitário em tempos de federalismo. Tese (Doutorado em História). Universidade Federal da Bahia, Salvador.

(2013). Lues venerea entre práticas e representações: saúde pública, doença e comportamento social nas serras jacobinenses. In: CHAVES, Cleide de Lima (Org.). História da saúde no interior da Bahia: séculos XIX e XX. Vitória da Conquista, BA: Edições UESB, pp. 115-146.

BATISTA, Ricardo dos Santos (2014). Mulheres livres: uma história sobre prostituição, sífilis e convenções de gênero e sexualidade. Salvador: EDUFBA.

BATISTA, Ricardo dos Santos \& SOUZA, C. M. C. (2015). Sífilis, Medicina e Organização Sanitária em Salvador - BA. In: MOTA, André; MARINHO, Maria Gariela S. M. C.; BERTOLLI FILHO, Cláudio. (Org.). As enfermidades e suas metáforas: epidemias, vacinação e produção de conhecimento. São Paulo, SP: Universidade de São Paulo -USP/ CD.G Casa de Soluções e Editora, v. VII, pp. 4970.

CARRARA, Sérgio (1996). Tributo a Vênus: a luta contra a sífilis no Brasil, da passagem do século aos anos 40. Rio de Janeiro: Ed. FIOCRUZ.

HOCHMAN, Gilberto (1998). Logo ali, no final da avenida: os sertões redefinidos pelo 
movimento sanitarista da Primeira República. História, Ciências, Saúde Manguinhos. Rio de Janeiro, vol. 5, supl., pp. 217-235. Disponível em: <http://www.scielo.br/scielo.php?script=sci_arttext\&pid=S0104597019980004000 12\&lng=en\&nrm=iso\&tlng=pt >. Acesso em: 1 mar. 2016.

(1993). Regulando os efeitos da interdependência: sobre as relações entre saúde pública e construção do Estado (Brasil 1910-1930). Estudos Históricos. Rio de Janeiro, vol. 6, n. 11, pp. 40-61. Disponível em: <http://bibliotecadigital.fgv.br/ojs/index.php/reh/article/view/1956/1095>. Acesso em: 1 fev. 2016.

JACOBINA, Ronaldo Ribeiro (2013). Memória histórica do centenário da Faculdade de Medicina da Bahia (2008): os professores encantados, a visibilidade dos servidores e o protagonismo dos estudantes da FMB. Salvador: UFBA, Faculdade de Medicina.

SÁ, Dominichi Miranda. (2009). Uma interpretação do Brasil como doença e rotina: a repercussão do relatório médico de Arthur Neiva e Belisário Penna (1917-1935). História, Ciências, Saúde - Manguinhos. Rio de Janeiro, vol. 16, supl. 1, pp. 183203. Disponível em: <http://www.scielo.br/scielo.php?script=sci_arttext\& pid=S0104-59702009000500009\&lng=pt\&nrm=iso\&tlng=pt $>$. Acesso em: $15 \mathrm{dez}$. 2015.

SANGLARD, Gisele (2008). Entre os salões e o laboratório: Guilherme Guinle, a saúde e a ciência no Rio de Janeiro, 1920-1940. Rio de Janeiro: Ed. FIOCRUZ.

SILVA, Aldo José Morais (1999). A percepção da moral oitocentista através dos registros eclesiásticos de óbito: elementos para uma história da cultura na saúde pública em Feira de Santana. Sitientibus. Feira de Santana, n. 21, pp. 101-116. Disponível em: <http://www2.uefs.br/sitientibus/pdf/21/a_percepcao_da_moral_oitocentista.pdf $>$. Acesso em: 24 mar. 2016.

SOUZA, Christiane Maria Cruz de (2013). Redes de poder e de solidariedade nos sertões da Bahia. In: CHAVES, Cleide de Lima (Org.). História da saúde no interior da Bahia: séculos XIX e XX. Vitória da Conquista-BA. Edições UESB, pp.43-82.

THIELEN, Eduardo Vilela et al (1992). A ciência a caminho da roça: imagens das expedições científicas do Instituto Oswaldo Cruz: 1911-1913. Rio de Janeiro: Casa de Oswaldo Cruz, Ed. FIOCRUZ.

Artigo recebido em 25 de março de 2016.

Aprovado em 12 de novembro de 2016. 